\title{
COMPACT LOG PERIODIC DIPOLE ARRAY ANTENNA FOR MULTIBAND APPLICATIONS USING S-FRACTAL CURVE
}

\author{
CH Murali Krishna ${ }^{1}$, P James Vijay ${ }^{2}$, M Ravi $^{3}$ \\ ${ }^{1}$ Assistant Professor, Department of ECE, Ramachandra College of Engineering, Andhra Pradesh, India \\ ${ }^{2}$ Assistant Professor, Department of ECE, S.R.K.R Engineering College, Andhra Pradesh, India \\ ${ }^{3}$ Assistant Professor, Department of ECE, Ramachandra College of Engineering, Andhra Pradesh, India
}

\begin{abstract}
Log periodic dipole array antennas are introduced for the development of broadband applications. In this paper, a low return loss $S$-shape fractal implemented on the printed log periodic dipole antenna is presented. This proposed design consists of log periodic slots in the ground plane and their self-complimentary structure is on the micro strip layer. This design offers multiband operation with fair values of return loss, VSWR, gain and impedance bandwidth in the entire range of frequency operation. The proposed $S$ shape LPDA design resonates at $2.54 \mathrm{GHz}, 2.90 \mathrm{GHz}, 3.70 \mathrm{GHz}, 4.28 \mathrm{GHz}, 4.98 \mathrm{GHz}, 5.52 \mathrm{GHz}, 6.42 \mathrm{GHz} .48 \mathrm{GHz}, 8.12 \mathrm{GHz}$, 8.82GHz and 9.40GHz for WiFi, WiMAX, WLAN, S-,C-and X-band applications with broad bandwidth.
\end{abstract}

Keywords: Fractal Structure, Log Periodic Dipole Array, Multiband, Broad Bandwidth, Radiation Efficiency. $* * *$

\section{INTRODUCTION}

Broadband wireless technologies have seen a rapid growth by the successful development of wireless applications like Bluetooth, WiFi, WLAN and WiMAX etc. The Federal Communication Commission (FCC) allotted a frequency band of $3.1-10.6 \mathrm{GHz}$ as a commercial Ultra-wide band (UWB) system.

Printed antennas are mostly used due to the ease of integration with microwave circuits and fabrication. A multiband antenna is an emerging device in many commercial applications which provides both transmission and reception at multiple frequencies. This antenna should be able to control the desired frequencies, impedance bandwidths, gain $\&$ polarizations.

Log periodic dipole array (LPDA) antennas are well known from1950's and their geometries are based on the rules of Isbell \& Carrel [1-3]. In the past years, a number of Printed LPDAs have been proposed and many techniques were implemented to realize UWB characteristics. In[4], printed Log-periodic dipole array was designed using Arlon AD250 substrate with dielectric constant $=2.5$ and thickness $=0.51 \mathrm{~mm}$ over the operating range $4-18 \mathrm{GHz}$ and UWB characteristics were obtained in the range 4.25$13.25 \mathrm{GHz}$ i.e., in a relative bandwidth greater than $100 \%$. In[5], Mode converter balunwas implemented on planar LPDA, this balun converts quasi TEM mode to full TEM mode with excitation current property (ECP), which operates in the range $1-4 \mathrm{GHz}$ to cover L \& S-bands. In[6], it presents a low profile log periodic monopole array designed with elliptical shape elements in the log periodic manner to operate over bandwidth $1.5-6.8 \mathrm{GHz}$ and end-fire radiation direction is achieved.
To achieve the multiband resonances in the antenna design, several methods are available. There are many examples like slots cut in the design, defected ground structures (DGS) and development of fractals etc. From many literature surveys, Koch fractal design [7-9], U-slot[10] and slots etched in the ground[11] are designed to obtain multiband resonances.

The primary focus of this paper is on low power wireless application bands. The dipole element can be redesigned into S-shape like a construction of Giuseppe peano fractal [12]. By altering this design, the characteristics of UWBPLPDA antenna have been converted to those of multiband PLPDA antenna.

\section{ANTENNA DESIGN METHODOLOGY}

Log periodic arrays consists radiating dipole elements arranged in Log-periodic manner. The frequency scaled logarithmically, there is only one region is radiating and is being shifted due to by varying the frequencies. The dimensions of the long and short dipole elements will achieve the operating bandwidth and another parameter is relative spacing or spacing factor $(\sigma)$, chosen from the directivity (D) and scaling factor $(\tau)$ graph. In this array, radiating elements are arranged in $180^{\circ}$ phase shift by adjacent elements; these elements are away from their resonances and are mismatched (in the transmission region).

A log periodic dipole array (LPDA) antenna has been designed over the frequency range $2-8 \mathrm{GHz}$ with the directivity $\mathrm{D}_{\mathrm{o}}=8 \mathrm{~dB}$, scaling factor $\tau=0.85$ and spacing factor $\sigma=0.157$. This antenna is milled on FR4 epoxy substrate with thickness $\mathrm{h}=1.6 \mathrm{~mm}$, dielectric constant, $\varepsilon_{\mathrm{r}}=4.4$ and loss $\operatorname{tangent} \tan \delta=0.02$. Figure 1 shows traditional / Euclidean 
LPDA antenna with $50 \Omega$ micro strip lines.For this LPDA design, the resonant length of the dipole element computed from the lowest operating frequency $\left(f_{\min }\right)$.The parameters shown in figure 1 are listed in table 1.

The average characteristic impedance of a dipole element is expressed as

$$
Z_{n}=\frac{\eta_{o}}{\pi}\left[\ln \left(\frac{L_{n}}{a_{n}}\right)-2.25\right]
$$

Where $L_{n}=$ length of the $n^{\text {th }}$ dipole element $a_{n}=$ radius of the $n^{\text {th }}$ dipole element

The width of the radiating dipole element computed as

$$
W_{n}=\pi * a_{n}
$$

The relation between the geometries of the LPDA antenna follows the following relation:

$$
\frac{1}{\tau}=\frac{l_{2}}{l_{1}}=\frac{l_{n+1}}{l_{n}}=\frac{R_{2}}{R_{1}}=\frac{R_{n+1}}{R_{n}}=\frac{w_{2}}{w_{1}}=\frac{w_{n+1}}{w_{n}}=\frac{s_{2}}{s_{1}}=\frac{s_{n+1}}{s_{n}}
$$

where $1_{n}=$ length of the $n^{\text {th }}$ element $\mathrm{R}_{\mathrm{n}}=$ distance between the two elements $\mathrm{W}_{\mathrm{n}}=$ width of the $\mathrm{n}^{\text {th }}$ element $\mathrm{S}_{\mathrm{n}}=$ center to center spacing betwen the two elements.

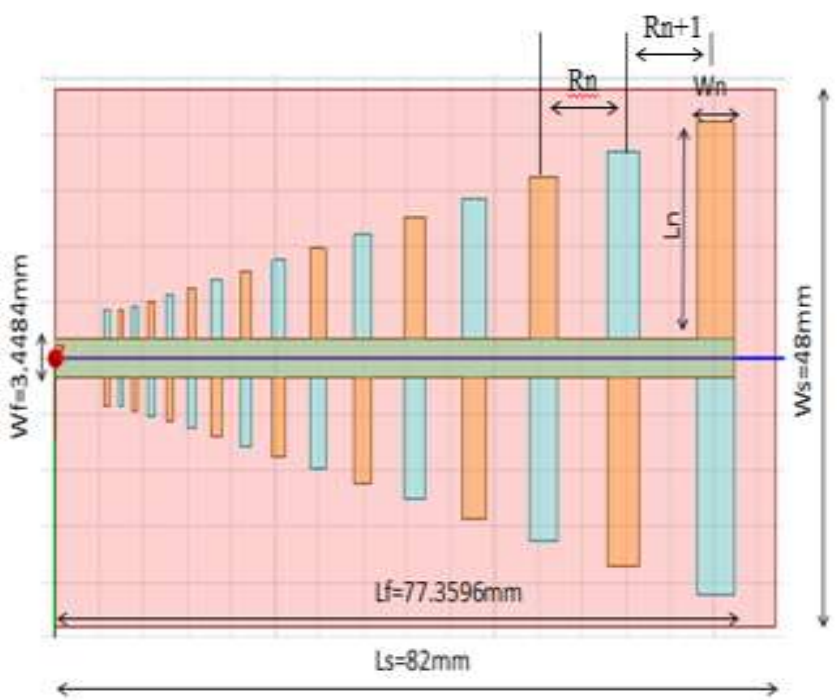

Fig-1: Designed printed log-periodic dipole array antenna for $2-8 \mathrm{GHz}$

Table-1: Geometry of designed printed LPDA with fractal implementations

\begin{tabular}{|l|l|l|l|l|l|}
\hline $\begin{array}{l}\text { Dipole } \\
(\mathrm{n})\end{array}$ & $\mathrm{L}_{\mathrm{n}}$ & $\mathrm{W}_{\mathrm{n}}$ & $\mathrm{R}_{\mathrm{n}+1}$ & $\mathrm{X}_{\mathrm{n}}$ & $\mathrm{Y}_{\mathrm{n}}$ \\
\hline 1 & 2.5464 & 0.5558 & ---- & 0.7275 & 0.3705 \\
\hline 2 & 2.9439 & 0.6426 & 1.5591 & 0.841 & 0.4284 \\
\hline
\end{tabular}

\begin{tabular}{|l|l|l|l|l|l|}
\hline 3 & 3.4033 & 0.7429 & 1.8487 & 0.9723 & 0.4952 \\
\hline 4 & 3.9345 & 0.8588 & 2.1372 & 1.1240 & 0.5725 \\
\hline 5 & 4.5485 & 0.9929 & 2.4708 & 1.2994 & 0.6619 \\
\hline 6 & 5.2584 & 1.1478 & 2.8564 & 1.5022 & 0.7652 \\
\hline 7 & 6.0791 & 1.327 & 3.3022 & 1.7367 & 0.8846 \\
\hline 8 & 7.0279 & 1.5341 & 3.8175 & 2.0077 & 1.0227 \\
\hline 9 & 8.1247 & 1.7735 & 4.4134 & 2.3211 & 1.1823 \\
\hline 10 & 9.3927 & 2.0503 & 5.1021 & 2.6834 & 1.3668 \\
\hline 11 & 10.8587 & 2.3703 & 5.8984 & 3.1022 & 1.5802 \\
\hline 12 & 12.5534 & 2.7403 & 6.819 & 3.5863 & 1.8268 \\
\hline 13 & 14.5126 & 3.1679 & 7.8833 & 4.1464 & 2.1119 \\
\hline 14 & 16.7776 & 3.6624 & 9.1136 & 4.7936 & 2.4415 \\
\hline 15 & 19.3961 & 4.234 & 10.536 & 5.5412 & 2.8226 \\
\hline
\end{tabular}

The dipole elements are modified into S-shape, which interned enhances the impedance bandwidth characteristics. By doing this phenomenon, the Ultra wide band (UWB) characteristics can be changed to multiband. Figure 2 shows the proposed antenna design with the parameters. The parameters are listed in table 1 . The overall size of the antenna is $82 \mathrm{~mm} \times 48 \mathrm{~mm} \times 1.6 \mathrm{~mm}$. This design is simulated using High frequency structure simulator (HFSS).

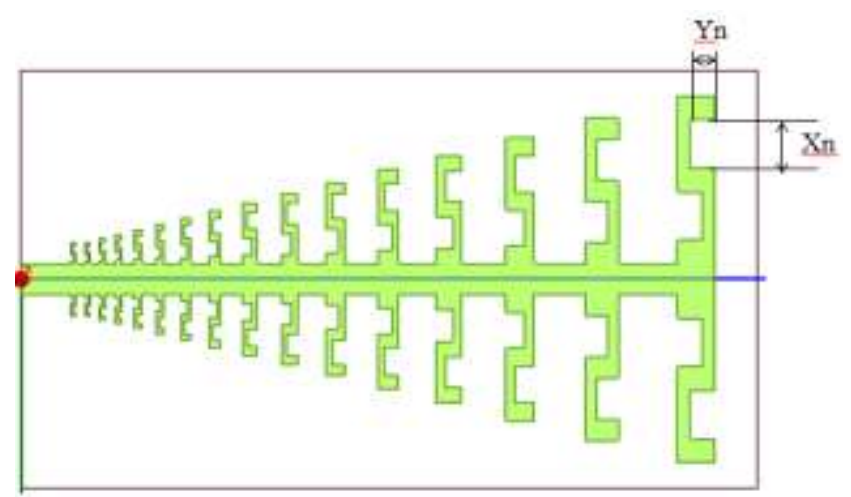

(a)

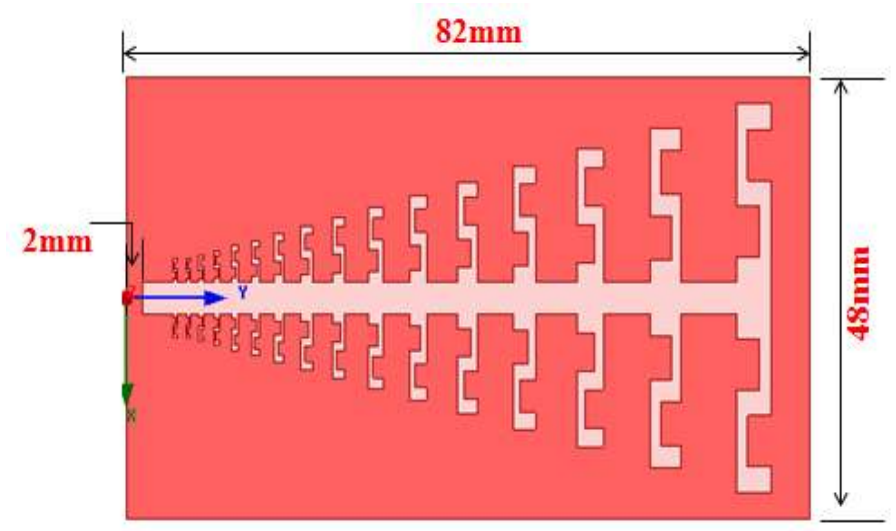

(b)

Fig-2: Proposed antenna design with parameters 


\section{RESULTS \& DISCUSSION}

\subsection{Return Loss Characteristics}

For the Euclidean LPDA antenna (as shown in figure 1), achieving UWB over $2.12 \mathrm{GHz}-14.44 \mathrm{GHz}$ with a bandwidth 12.32GHz. Figure 3 shows the impedance reflection coefficient characteristics and figure 4 shows the VSWR for the initial design.

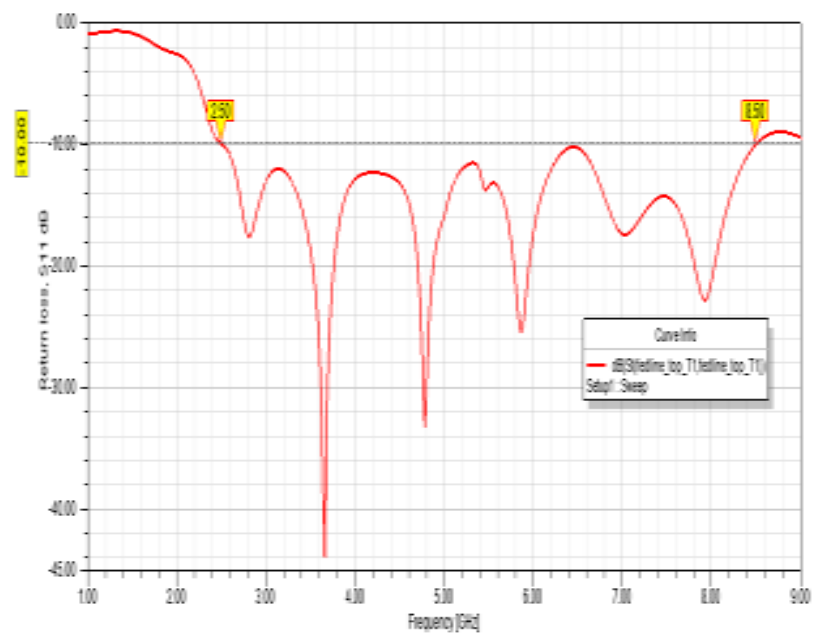

Fig-3: Return loss characteristics for initial design

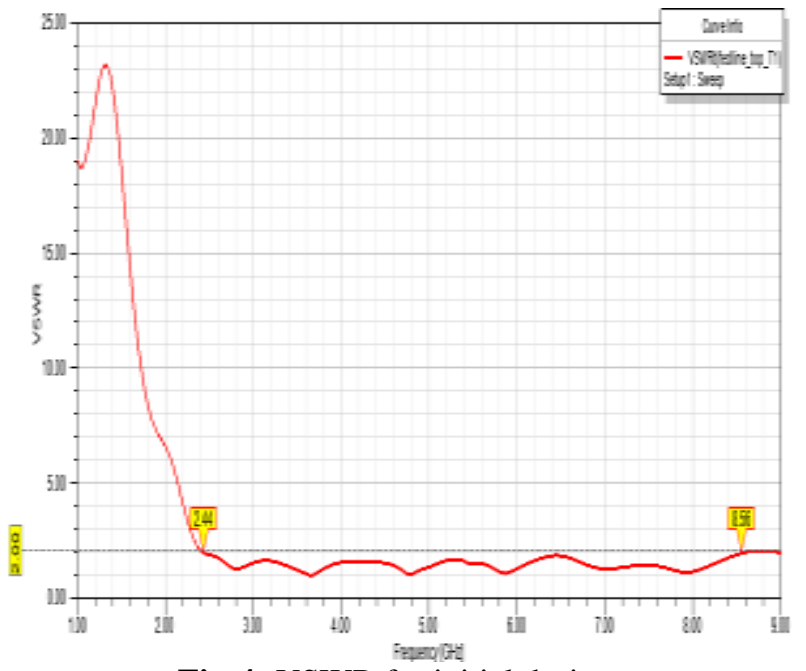

Fig-4: VSWR for initial design

Figure 5 shows the return loss characteristics of proposed design.The self-complimentary structure is etched in the ground to enhance the bandwidth and gain characteristics. Figure 6 shows the VSWR of the proposed design.

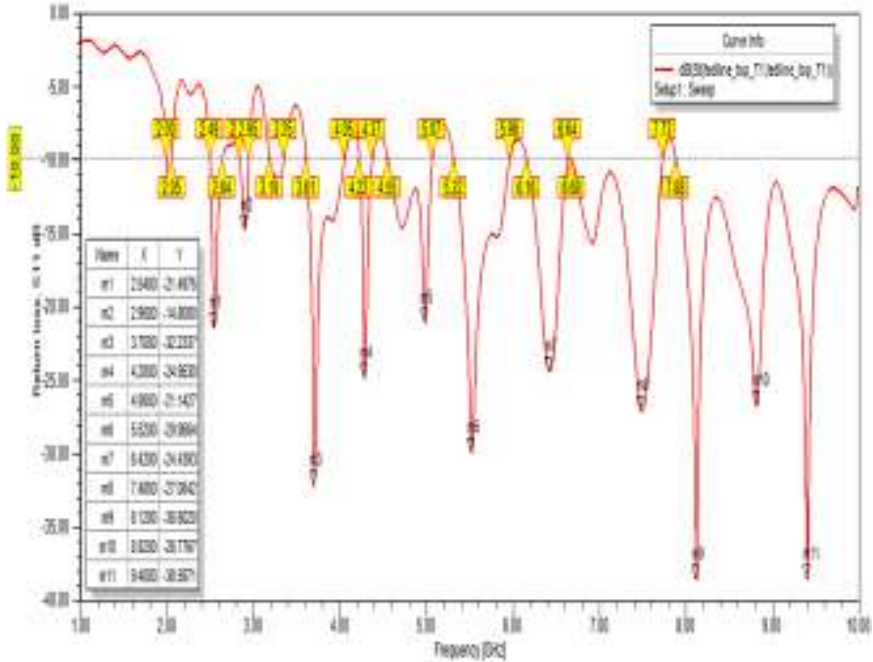

Fig-5: Return loss characteristics of the proposed antenna design

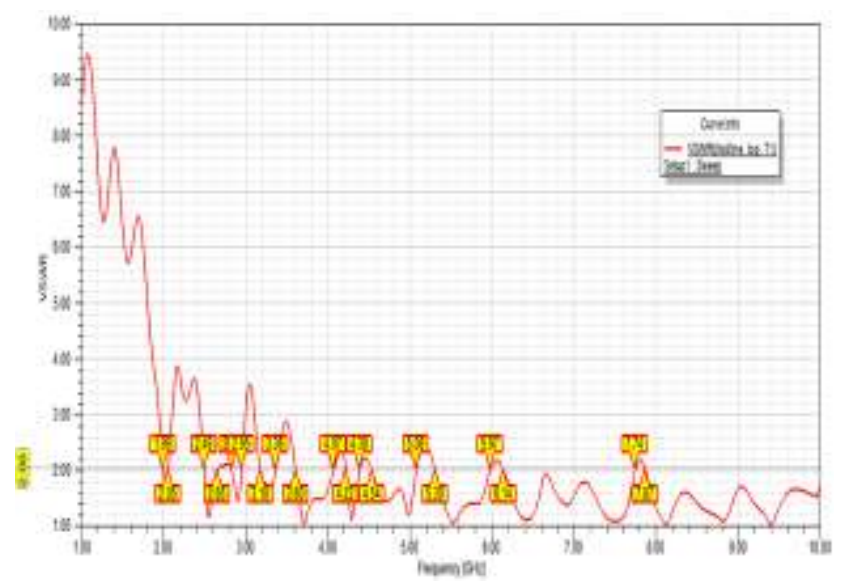

Fig-6: VSWR of the proposed antenna design

The impedance bandwidths of the proposed antenna design are $\quad 150 \mathrm{MHz}(2.49-2.64 \mathrm{GHz}), \quad 90 \mathrm{MHz}(2.84-2.95 \mathrm{GHz})$, 440MHz(3.61-4.05GHz), $150 \mathrm{MHz}(4.22-4.37 \mathrm{GHz})$, $520 \mathrm{MHz}(4.55-5.07 \mathrm{GHz}), \quad 640 \mathrm{MHz}(5.32-5.96 \mathrm{GHz})$, $480 \mathrm{MHz}(6.16-6.64 \mathrm{GHz})$ at their resonant frequencies are $2.54 \mathrm{GHz}, \quad 2.90 \mathrm{GHz}, \quad 3.70 \mathrm{GHz}, \quad 4.28 \mathrm{GHz}, \quad 4.98 \mathrm{GHz}$, $5.52 \mathrm{GHz}, \quad 6.42 \mathrm{GHz}$ and $7.48 \mathrm{GHz}$ with reflection coefficients $-21.49 \mathrm{~dB},-14.80 \mathrm{~dB},-32.23 \mathrm{~dB},-24.95 \mathrm{~dB}$, $21.14 \mathrm{~dB},-29.95 \mathrm{~dB},-24.43 \mathrm{~dB}$ and $-27.08 \mathrm{~dB}$ respectively and also one broad band with resonances at $8.12 \mathrm{GHz}$, $8.82 \mathrm{GHz}, 9.40 \mathrm{GHz}$ with $-38.60 \mathrm{~dB},-26.77 \mathrm{~dB},-38.59 \mathrm{~dB}$ respectively.

\subsection{Far Field Characteristics}

The corresponding peak gains of the proposed antenna are $0.05 \mathrm{~dB}, 0.66 \mathrm{~dB}, 1.07 \mathrm{~dB}, 1.54 \mathrm{~dB}, 1.87 \mathrm{~dB}, 2.96 \mathrm{~dB}, 3.46 \mathrm{~dB}$, $4.10 \mathrm{~dB}, 3.30 \mathrm{~dB}, 3.43 \mathrm{~dB}$ and $2.81 \mathrm{~dB}$ at their corresponding resonant frequencies $2.54 \mathrm{GHz}, \quad 2.90 \mathrm{GHz}$, $3.70 \mathrm{GHz}, 4.28 \mathrm{GHz}, 4.98 \mathrm{GHz}, 5.52 \mathrm{GHz}, 6.42 \mathrm{GHz} 7.48 \mathrm{GHz}$, $8.12 \mathrm{GHz}, 8.82 \mathrm{GHz}$ and $9.40 \mathrm{GHz}$ respectively. The direction of $3 \mathrm{D}$ gain plots are shown in figure 7 . 


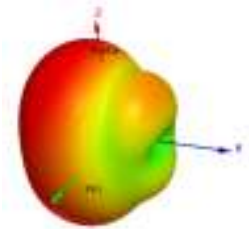

(a)

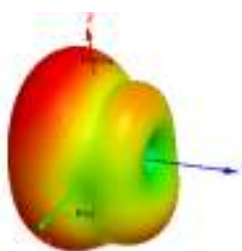

(d)

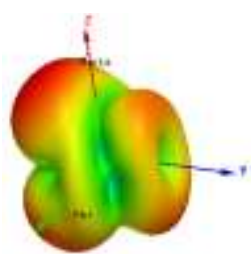

(g)

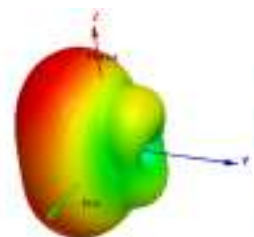

(b)

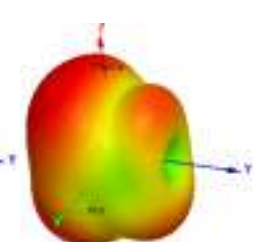

(e)

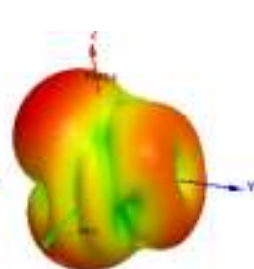

(h)

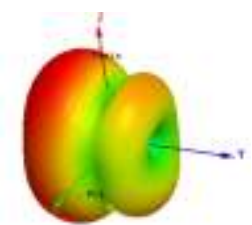

(c)

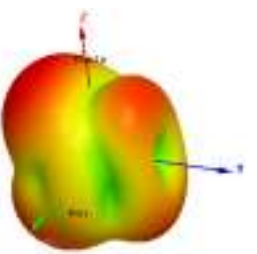

(f)

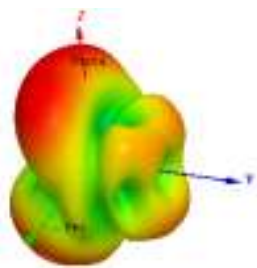

(i)

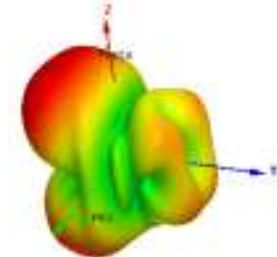

(j)

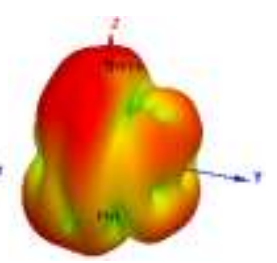

(k)
Fig-7:Simulated 3D gain polar plots of the proposed antenna at a) $2.54 \mathrm{GHz}$, b) $2.90 \mathrm{GHz}$, c) $3.70 \mathrm{GHz}$, d) $4.28 \mathrm{GHz}$, e) $4.98 \mathrm{GHz}, \mathrm{f}) 5.52 \mathrm{GHz}, \mathrm{g}) 6.42 \mathrm{GHz}, \mathrm{h}$ ) $7.48 \mathrm{GHz}$, i) $8.12 \mathrm{GHz}$, j) $8.82 \mathrm{GHz}, \mathrm{k}) 9.40 \mathrm{GHz}$

The radiation patterns for both E-plane and H-plane at their resonant frequencies are shown in figure 8.

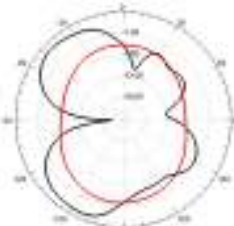

(a)

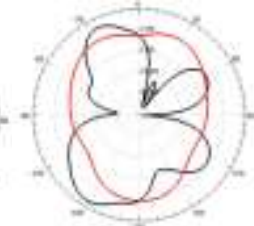

(b)

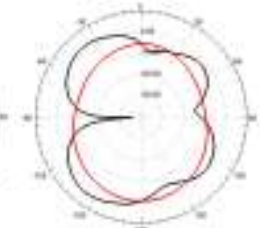

(c)

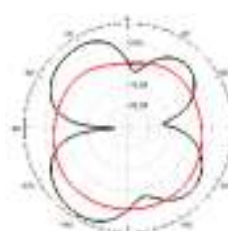

(d)

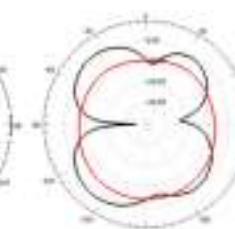

(e)

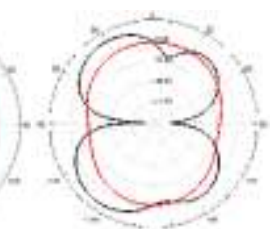

(f)

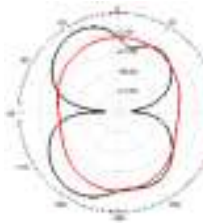

(g)

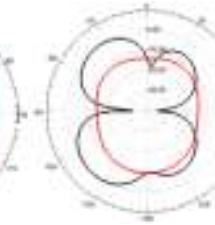

(h)

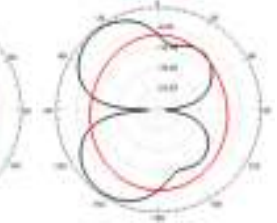

(i)

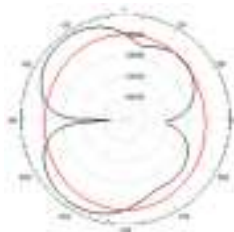

(j)

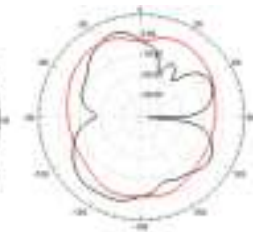

(k)
Fig-8:simulated radiation patterns of the proposed antenna at a) $2.54 \mathrm{GHz}$, b) $2.90 \mathrm{GHz}$, c) $3.70 \mathrm{GHz}$, d) $4.28 \mathrm{GHz}$, e) $4.98 \mathrm{GHz}, \mathrm{f}) 5.52 \mathrm{GHz}, \mathrm{g}) 6.42 \mathrm{GHz}, \mathrm{h}) 7.48 \mathrm{GHz}, \mathrm{i})$ $8.12 \mathrm{GHz}, \mathrm{j}$ ) $8.82 \mathrm{GHz}, \mathrm{k}$ ) $9.40 \mathrm{GHz}$ (red-elevation plane, black-azimuth plane)

\subsection{Surface Current Distribution}

For more understanding the role of dipole elements in improving the antenna gain and bandwidth, the magnitude surface current distribution inside the dipole elements is shown in figure 9. At higher frequencies, smaller elements are radiated and at low frequencies, larger elements are radiated. The modified element compared with the dipole element, there are more discontinuous on the dipole due to this current flow increases in the proposed design. So, radiation efficiency has been improved.

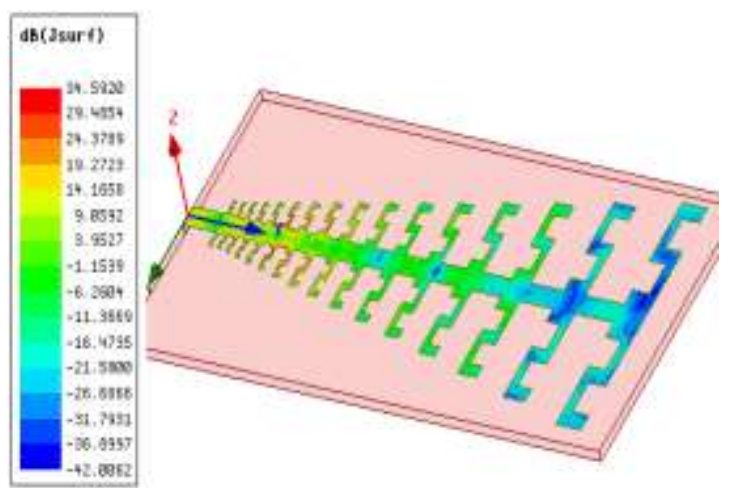

(a)

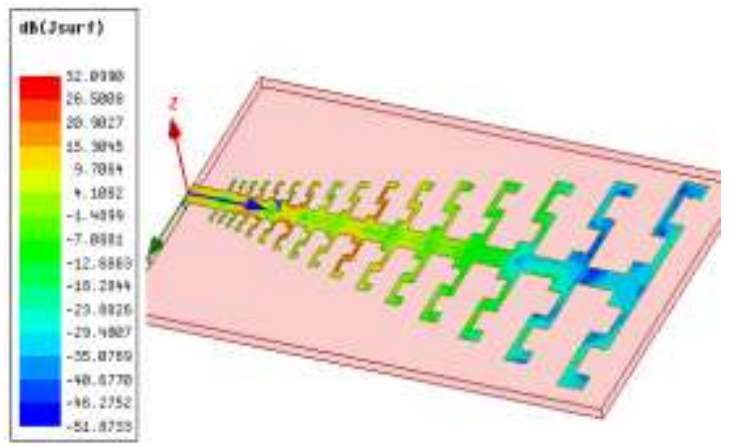

(b) 


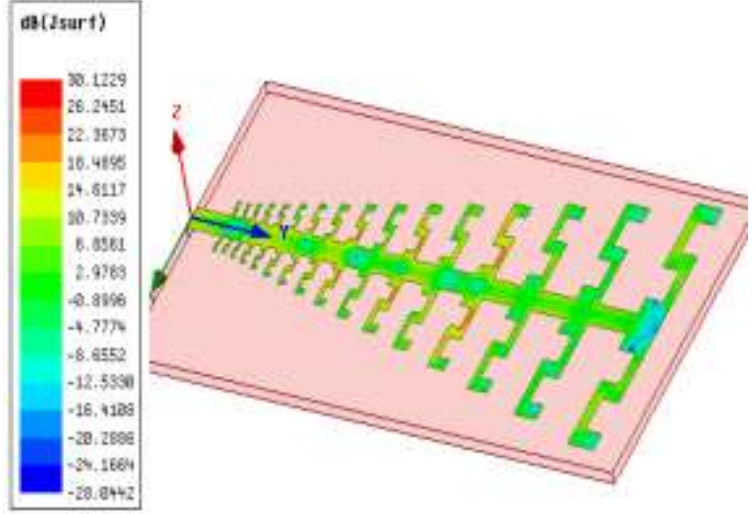

(c)

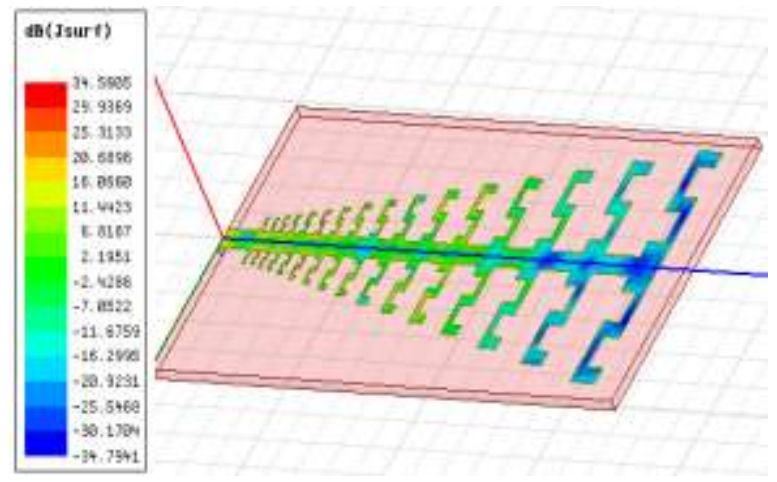

(d)

Fig-9: Surface current distribution at a) $3.70 \mathrm{GHz}$ b) $5.52 \mathrm{GHz}$ c) $7.48 \mathrm{GHz}$ d) $9.40 \mathrm{GHz}$

\section{CONCLUSION}

The log periodic S-shape fractal dipole antenna for multiband characteristics was proposed with simulated results. The fractal implemented for LPDA to gain miniaturization in size, enhanced the bandwidth and improved the number of resonant frequency bands. The characteristics of antenna such as return loss, VSWR and far-field radiation characteristics have been simulated at resonant frequencies.The radiation efficiency of the proposed antenna has been improved from the magnitude surface current distribution of the structure. The proposed antenna operates at $2.54 \mathrm{GHz}, 2.90 \mathrm{GHz}, 3.70 \mathrm{GHz}, 4.28 \mathrm{GHz}$, $4.98 \mathrm{GHz}, 5.52 \mathrm{GHz}, 6.42 \mathrm{GHz}, 7.48 \mathrm{GHz}, 8.12 \mathrm{GHz}, 8.82 \mathrm{GHz}$ and $9.40 \mathrm{GHz}$ with better impedance matching. Hence, the proposed antenna is most suitable for multiband characteristics of antenna and used for various applications like PCS, DCS, WiFi, WLAN, WiMAX, S- \& C-band applications.

\section{REFERENCES}

[1] Carrel, R., "The design of log-periodic dipole antennas," IRE International ConventionRecord, Vol. 9, 61-75, 1961.

[2] Isbell, D. E., "Log periodic dipole arrays," IEEE Transactions on Antennas andPropagation, Vol. 8, 260-267, 1960.
[3] Carrel, R.,Analysis and design of the log-periodic dipole antenna," Ph.D. Dissertation,University of Illinois, 1961.

[4] Giovanni A.Casula, Paolo Maxia, Giuseppe Mazzarella, Giorgio Montisci, "Design of APrinted Log-Periodic Dipole Array for Ultra-Wide Band Applications", PIERS C, vol.38,15-26, 2013.

[5] M.I.Mirzapour, S.M.J.Razavi and S.H.MohseniArmaki, "Ultra-wideband planar LPDAantenna with mode converter balun", IEEE, $5^{\text {th }}$ June 2014, vol.50, No.12, pp 848-850.

[6] Zhenxin Hu, ZhongxiangShen, Wen Wu, Jian Lu, "Low-profile Log-periodic monopolearray", IEEE transactions on Antennas and propagation, vol.63, No.12, Dec15.

[7] Chun-Te Wu, Wei-Zhe Dai, Cheng-Nan Chiu, HanChang Hsieh, "BandwidthEnhancement of Micro strip Fed Koch Snowflake Fractal Slot Antenna", APEMC2015.

[8] DimitrisE.Anagnostou, John Papapolymerou, Manos M.Tentzeris, ChristosG.Christodoulou, "A Printed Log-Periodic Koch Dipole Array [LPKDA]", IEEEAntennas and Wireless Propagation Letters, vol.7, 2008.

[9] M.N.A.Karim, M.K.A.Rahim,H.A.Majid, O.Ayop, M.Abu, F.Zubir, "Log PeriodicFractal Koch Antenna forUHF Band Applications", PIER 100, 201-218, 2010.

[10] RuiXu, Jian-Ying Li, Jiang-Jun Yang, Kun Wei, Yang-Xiao Qi, "A Design of U-ShapesSlot Antenna with Broadband Dual Circularly Polarized Radiation", IEEE Transactionson Antennas And Propagation, 2017.

[11] Elena Abdo-Sanchez, Jaime Esteban, Teresa M.Martin- Guerreto, Carloy Camacho-Penelosa, Peter S.Hall, "A Novel Planar Log-Periodic Array Based On The WidebandComplementary Strip-slot Element", IEEE Transactions on Antennas and Propagation,vol.62, No.11, Nov 2014.

[12] HomayoonOraizi, ShahramHedayati, "Miniaturization of Micro strip Antennas by theNovel Application of the Giuseppe Peano Fractal Geometries", IEEE Transactions onAntennas and Propagation, vol.60, No.8, August2012.

\section{BIOGRAPHIES}

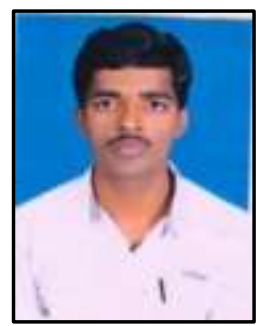

CH.MURALI KRISHNA is presently working as an assistant professor in the department of ECE, Ramachandra college of engineering, Eluru. $\mathrm{He}$ received his M.Tech degree in Electronics and Communication Engineering from S.R.K.R. Engineering College, Bhimavaram, India in 2018. He obtained his bachelor of technology in Electronics and Communication Engineering from SreeVahini Institute of Science and Technology, Tiruvuru, India in 2015. He is currently working on Micro strip patch antennas design for 
wireless communications with various feeding techniques. Present focusing on optimization algorithms and is planning to do Ph.D in near future in the same domain.

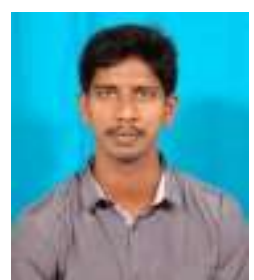

P.JAMES VIJAY is presently working as an assistant professor in the department of ECE, S.R.K.R. Engineering college, Bhimavaram. He has three years teaching experience. He received his M.Tech degree in Electronics and Communication Engineering from S.R.K.R. Engineering College, Bhimavaram, India in 2014. His research areas interests include microstrip patch antennas, power dividers and slot antennas.

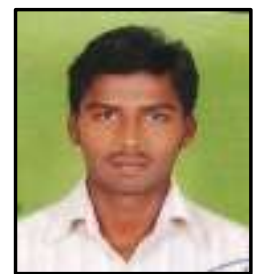

M.RAVI is presently working as an assistant professor in the department of ECE, Ramachandracollege of engineering, Eluru. He has more than eight years of teaching experience in various subjects. His interest research areas are Image processing, signal processing and wave propagation. 